\title{
Characterization of exhaled nitric oxide: introducing a new reproducible method for nasal nitric oxide measurements
}

\author{
J.P. Palm*,\#, P. Graf*, J.O.N. Lundberg*, K. Alving*
}

\begin{abstract}
Characterization of exhaled nitric oxide: introducing a new reproducible method for nasal nitric oxide measurements. J.P. Palm, P. Graf, J.O.N. Lundberg, K. Alving. C)ERS Journals Ltd 2000.

ABSTRACT: Nitric oxide (NO) is present in the human nasal airways and has been suggested to originate primarily from the paranasal sinuses. The aim of this study was to establish a new and reproducible method for measurement of nasal NO.

Through repeated single-breath measurements the intra- and inter-individual variations of NO levels in nasally (into a tightly fitting mask covering the nose) and orally exhaled air were determined in healthy humans. Variations due to the methods used were investigated. The contribution of oral NO to the nasal exhalations by introducing a mouthwash procedure was also studied.

This study shows distinct individual values of NO in nasally and orally exhaled air of healthy humans. Some diurnal variability was also found with a rise in NO in nasally and orally exhaled air over the day, but no, or little, day-to-day variability when comparing the results from separate mornings. There was no correlation between NO levels in nasally and orally exhaled air, whereas there was a strong correlation between NO levels in air exhaled through the left and right nostril. The levels of NO in air exhaled at $0.17 \mathrm{~L} \cdot \mathrm{s}^{-1}$ through either nostril separately were higher than in air exhaled at the same flow rate through both nostrils simultaneously. After the introduction of a mouthwash procedure the level of NO in orally, but not nasally exhaled air was reduced.

To conclude the method using nasal exhalation into a nose mask is highly reproducible. It is also suggested that subtracting the level of NO in orally exhaled air, after mouthwash, from that in nasally exhaled air, would adequately reflect nasal NO levels.
\end{abstract}

Eur Respir J 2000; 16: 236-241.

*Dept of Physiology and Pharmacology, Karolinska Institute, Sweden, "Dept of Otorhinolaryngology, Huddinge University Hospital, Sweden.

Correspondence: J.P. Palm, Dept of Physiology and Pharmacology, Karolinska Institutet, Sweden. Fax: 468332278

Keywords: Diurnal variation

exhaled air

gender

nasal nitric oxide

oral nitric oxide

volume flow rate

Received: December 311999

Accepted after revision April 252000

The study was supported by Recip AB, the Swedish Medical Research Council (project no 10354), the Swedish Heart-Lung Foundation, and the Swedish Foundation for Allergy Research and Health Care Science.
Nitric oxide (NO) is present in orally exhaled air [1] and in the human nasal airways [2], and has been suggested to originate primarily from the paranasal sinuses, where high concentrations have been detected compared to lower order animals [3-5]. Several studies have been carried out in order to assess nasal NO levels quantitatively - both in healthy and diseased states and after pharmacological treatment [6-13]. Consensus has been reached on recommendations for nasal NO measurements, suggesting a method of direct nasal aspiration (or insufflation) [14]. The authors believe, that knowledge of normal nasal NO output is limited, and have therefore attempted to investigate nasal air flow dynamics further, using a method that may better represent normal transnasal air flow dynamics and, thus, normal sinonasal communication. Furthermore, even though the same sampling flow rate has been used, a large variation in normal values has been reported, using the aspiration technique [15]. Therefore a setup for nasal exhalation of air into a tightly fitting nose mask, a method resembling that recommended for measurements of NO in orally exhaled air [16] has been used. Using these methods the levels of NO in healthy human subjects in nasally and orally exhaled air was measured, to determine the normal bio- logical variation in NO levels and variations due to errors of measurement. Finally, since it has been shown that there is a salivary contribution to orally exhaled NO [17], the effect of a mouthwash procedure on levels of nasally and orally exhaled NO was studied. All this, in order to examine the possibility of introducing an alternative method, where the level of orally exhaled NO is subtracted from nasally exhaled NO, to get a representative value of nasal NO.

\section{Methods}

Measurements of NO levels in nasally and orally exhaled air at different times of the day and on different days

Subjects and setting. Fifteen healthy subjects, seven (nonpregnant) females and eight males, aged 20-30 yrs, were recruited for the study. Before the trial, each subject's medical history was taken, after which an examination was performed including blood pressure, lung and heart auscultation, and an ear, nose and throat examination. All subjects were healthy nonsmokers and were not taking any 
medication. They had no history of allergy or other rhinological disease and no one had had a common cold or sinusitis the month before entering the trial. On rhinoscopy, no signs of mucosal inflammation or anatomical changes were noted. After this first examination the subjects were asked to return to the clinic 1,3 and 7 days later, at $07: 30 \mathrm{~h}$. The subjects were allowed to rest for $\geq 30 \mathrm{~min}$ before the start of the study. All measurements were performed between 08:00 $\mathrm{h}$ and 17:00 $\mathrm{h}$; morning values were collected between 08:00 $\mathrm{h}$ and 10:00 h, midday values between 11:30 $\mathrm{h}$ and 13:30 $\mathrm{h}$ and afternoon values between 15:00 and 17:00. Measurements were carried out on all subjects each morning whereas the measurements over the day were performed on a day randomly selected out of the three possible. For the duration of the testing the subjects were confined to three waiting rooms adjacent to the laboratory, allowed no exercise and given only cold meals (sandwiches) and beverages (sparkling water, light beer), being served neither coffee nor tea. The procedures employed in this study have been reviewed and approved by the local ethics committee.

Measurements of NO in exhaled air. The NO measurements were made with a chemiluminescence technique, and air sampling was measured according to the recommendations described for orally exhaled NO in the European Respiratory Society (ERS) Task Force Report using a single-breath exhalation [16]. Briefly, compressed NOfree air was continuously flushed into a non-diffusing gas collection bag (Hans Rudolph Inc., Kansas City, USA) at a rate of $2-3 \mathrm{~L} \cdot \mathrm{min}^{-1}$. The bag was connected via a tube to a Y-piece with a one-way valve, which in turn was adapted to a tightly fitting nose mask. For the measurement of NO in nasally exhaled air, the subjects (in seated position) took a deep breath through the nose, thus, inhaling $\mathrm{NO}$-free air from the gas collection bag, then nasally exhaled against a linear resistance of $50 \mathrm{cmH}_{2} \mathrm{O} \cdot \mathrm{L}^{-1} \cdot \mathrm{s}^{-1}$ (Hans Rudolph Inc.) for a period of $15 \mathrm{~s}$ into the nose mask, which was connected to a linear pneumotachymeter (Hans Rudolph Inc.), where flow and pressure were measured. A fraction of the exhaled air was sampled into the NO analyser (Eco Physics model 77 AM, Ecophysics, Dürnten, Switzerland) at a flow rate of $\sim 0.1 \mathrm{~L} \cdot \mathrm{min}^{-1}$. These signals were sent to a computer with specially designed software (Exhaled Breath Analyser, Aerocrine AB, Stockholm, Sweden) that calculated the mean NO plateau. The recordings were instantly visualized on a computer screen, which enabled the subjects to adjust the exhalation to the flow or pressure curve. The subjects were told to keep the pressure 9-11 $\mathrm{cmH}_{2} \mathrm{O}$ throughout the exhalation, which resulted in a mean flow rate of $0.17 \mathrm{~L} \cdot \mathrm{s}^{-1}$. The linear resistance was chosen in order to obtain upward closure of the soft palate during oral exhalation and keeping the conditions similar during nasal exhalation with downward closure of the soft palate. The NO level would show a stable plateau after an initial peak in all measurements. The subjects were then asked to repeat the same procedure with a plug of cotton wool gently introduced by the examiner first in the subject's left then right vestibulum of the nostril, avoiding contact with the nasal mucosa. For the measurement of $\mathrm{NO}$ in orally exhaled air the nose mask was replaced by a mouthpiece through which the subjects were first asked to inhale through the mouth followed by an oral exhalation under the same conditions as above. All measurements were repeated three times at each timepoint. The chemiluminescence NO analyser was calibrated each morning by a standard two-point calibration using a reference gas of 10 parts per million (ppm) NO (AGA AB, Lidingö, Sweden). All measurements were supervised by the same examiner. All subjects completed the study and no one had to be excluded due to upcoming disease. Throughout the study, NO concentrations in ambient air were $<1$ parts per billion $(\mathrm{ppb})$ and the baseline drift of the chemiluminescence $\mathrm{NO}$ analyser was $< \pm 0.5 \mathrm{ppb}$.

\section{Effects of a mouthwash procedure}

Twenty-five healthy nonsmoking subjects, eight (nonpregnant) females and 17 males, mean age 40 yrs (24-59 yrs) were recruited for this study. The levels of $\mathrm{NO}$ in orally exhaled air was measured twice before, and twice 1 min after a 1-min mouthwash with $2 \mathrm{~g}(10 \%)$ sodium bicarbonate in $20 \mathrm{~mL}$ of distilled water. In this study the same setup for the measurement of NO in exhaled air was used as described above, with exhalation performed against a resistance of $100 \mathrm{cmH} \mathrm{H}_{2} \mathrm{O} \cdot \mathrm{L}^{-1} \cdot \mathrm{s}^{-1}$ and the subjects were told to keep the flow rate $0.09-0.11 \mathrm{~L} \cdot \mathrm{s}^{-1}$, which resulted in an oral pressure of $10-12 \mathrm{cmH}_{2} \mathrm{O}$.

\section{Statistics}

Nonparametric statistics with two-sided p-values were used throughout the study, based on the mean NO values at each time point. For the analysis of repeated measurements Friedman's test was used, and followed by Wilcoxon signed rank sum test when significant. For correlation analysis, Spearman rank correlation was used. For sex analysis Mann-Whitney U test was used. For the analysis of change in an individual and of methodological variation due to mouthwash, Wilcoxon signed rank sum test was used, based on the individual NO values at each time point. A pvalue of $<0.05$ was considered significant. Statistical analyses and figures were made using Prism by Graph Pad Software Inc. (Graph Pad, San Diego, CA, USA). Results are given as mean $\pm \mathrm{SEM}$.

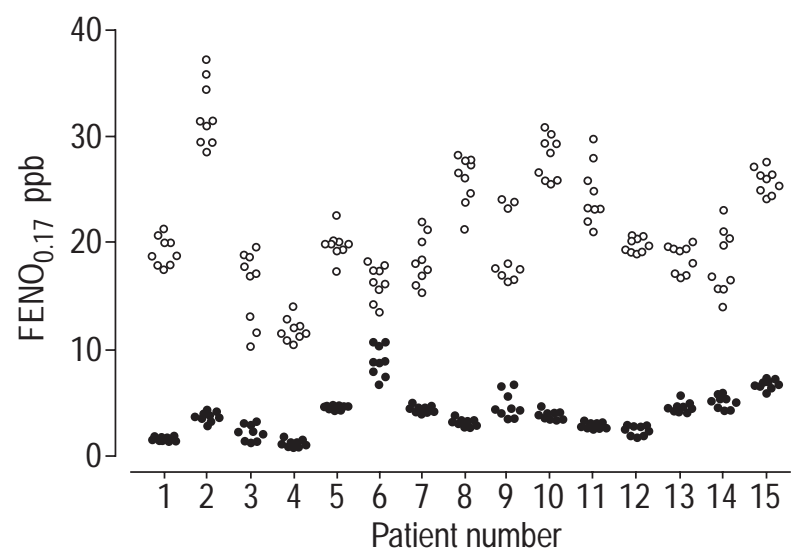

Fig. 1. - NO in nasally $(\bigcirc)$ and orally $(\bigcirc)$ exhaled air of fifteen healthy subjects measured in triplicate at three time-points during one single day, each separate measurement is presented. No correlation was found between levels of NO in nasally and orally exhaled air $(r=0.004, p=0.99$; Spearman rank correlation). FENO0.17: exhaled concentration of NO at a flow rate of $0.17 \mathrm{~L} \cdot \mathrm{s}^{-1}$; ppb: parts per billion. 


\section{Results}

NO levels in nasally and orally exhaled air at different times of the day and on different days

Each subject showed consistent individual values of NO in nasally and orally exhaled air throughout the study. Based on measurements at three time-points during one single day, the separate readings ranged $10-37 \mathrm{ppb}$ in nasally exhaled NO and $0.5-10 \mathrm{ppb}$ in orally exhaled NO (fig. 1). Based on the mean of three measurements at each time-point during one single day NO in nasally exhaled air ranged $12-32 \mathrm{ppb}$ and in orally exhaled air $0.8-8.5$ ppb. Thus, almost a 3-fold inter-individual difference in nasally exhaled NO and a 10 -fold difference in orally exhaled NO was noted.

There was a slight but significant diurnal variation as evinced by an increase of NO in nasally exhaled air over the day. The mean value at midday differed from that in the morning and there was a trend towards a difference in the mean afternoon value compared to that at midday (fig. $2 \mathrm{a}$ ). There was also a slight but significant increase of NO in orally exhaled air over the day. The mean value at midday differed from that in the morning and the mean value in
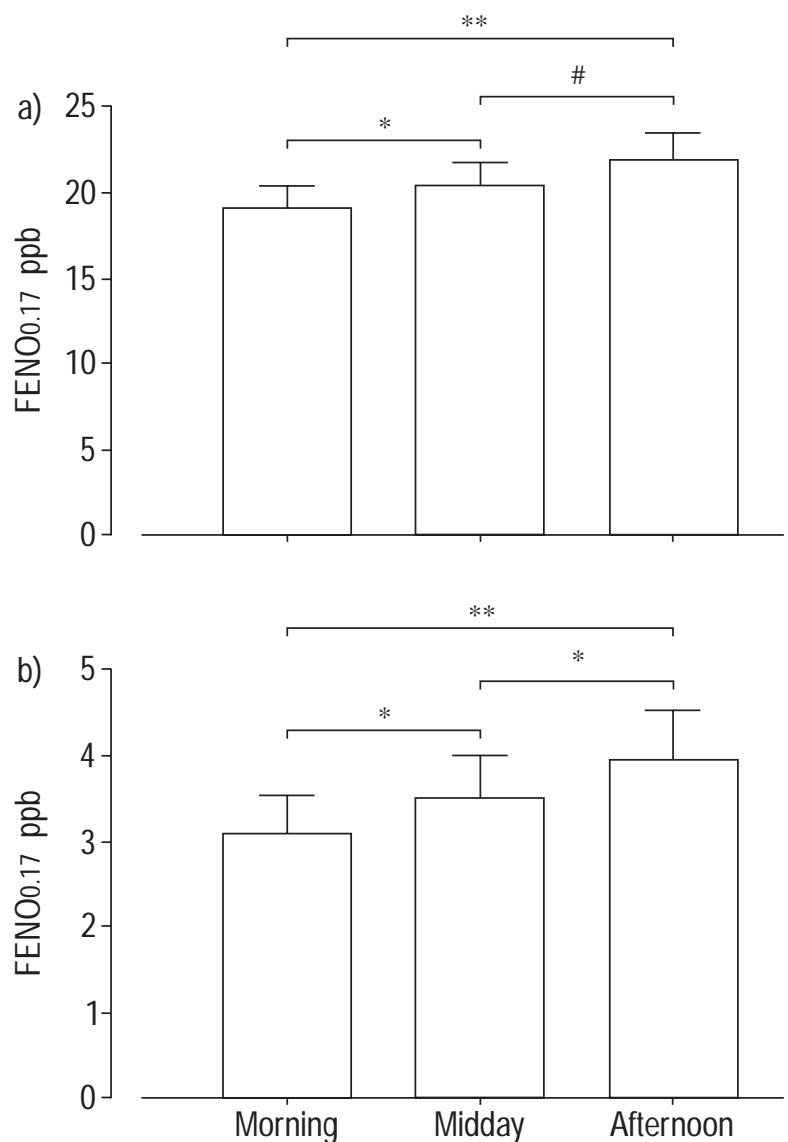

Fig. 2. - a) NO in nasally exhaled air of 15 healthy subjects measured at three times one day, showing a $15 \%$ increase over the day $(p=0.002$; Friedman's test). b) NO in orally exhaled air of 15 healthy subjects measured at three times one day, showing a $23 \%$ increase over the day $\left(\mathrm{p}=0.001\right.$; Friedman's test). $*: \mathrm{p}<0.05 ; * *: \mathrm{p}<0.01 ; * * *: \mathrm{p}<0.001,{ }^{\#}$ : $\mathrm{p}=0.6$ compared to previous time-point; Wilcoxon signed rank test). FENO0.17: exhaled concentration of NO at a flow rate of $0.17 \mathrm{~L} \cdot \mathrm{s}^{-1}$; ppb: parts per billion.
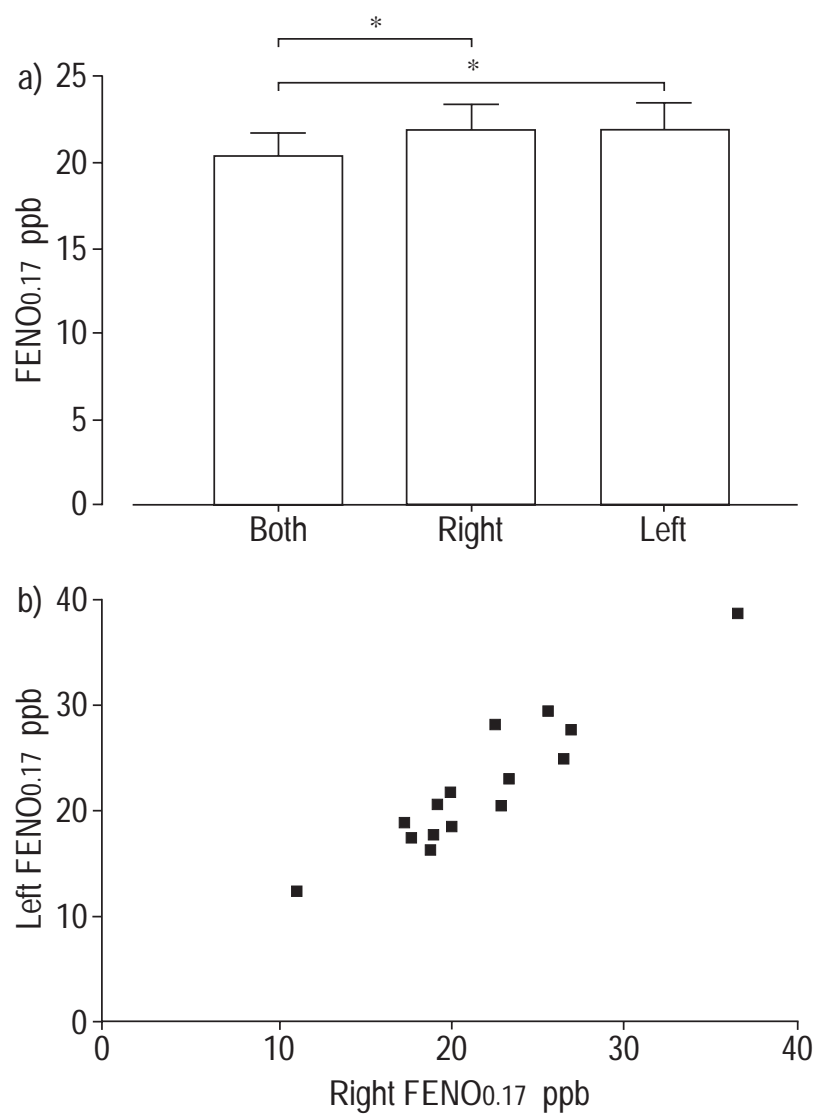

Fig. 3. - a) NO in exhaled air of 15 healthy subjects as measured from first both nostrils and then the right and left nostril separately. Values are presented as the mean of measurements at three time-points on one single day. *: $\mathrm{p}<0.05$; Wilcoxon signed rank sum test. b) Correlation of $\mathrm{NO}$ in nasally exhaled air of fifteen healthy subjects measured between the right and left nostril. Values are presented as the mean of measurements at three time-points on one single day $(r=0.87, p<0.0001$; Spearman rank correlation). FENO0.17: exhaled concentration of $\mathrm{NO}$ at a flow rate of $0.17 \mathrm{~L} \cdot \mathrm{s}^{-1}$; ppb: parts per billion.

the afternoon differed from that at midday (fig. 2b). Notably, the increase over the day was consistent in all subjects.

There was no day-to-day variation in nasally exhaled NO levels on three different mornings $(20 \pm 1.4,21 \pm 1.5,19 \pm 1.7$; $\mathrm{p}=0.15$; Friedman's test). However, there was a slight but significant difference in orally exhaled NO levels on the three mornings $(3.2 \pm 0.5,3.4 \pm 0.6,2.7 \pm 0.5 \mathrm{ppb} ; \mathrm{p}<0.05$; Friedman's test). The mean value on the morning of day 7 differed from that on day 3, that is, the Monday differed from the Thursday $(\mathrm{p}<0.05$; Wilcoxon signed rank sum test). Methodological variability as described by the within-subject coefficient of variance (CV) of $\mathrm{NO}$ in nasally exhaled air based on the morning values the day the subject was to be further analysed over the day was $5.1 \pm$ $0.8 \%$; $(0.6-10 \%)$ and in orally exhaled air was $9.0 \pm 1.0 \%$; $(4.0-17 \%)$.

Correlation statistics and sex analysis was performed, based on the mean of measurements at three time-points during one day. There was no correlation between nasally and orally exhaled NO levels $(r=0.004, p=0.99$; Spearman rank correlation). A slight difference was seen when NO levels in air exhaled through both nostrils to those in air from either the right or the left nostril were compared (fig. 


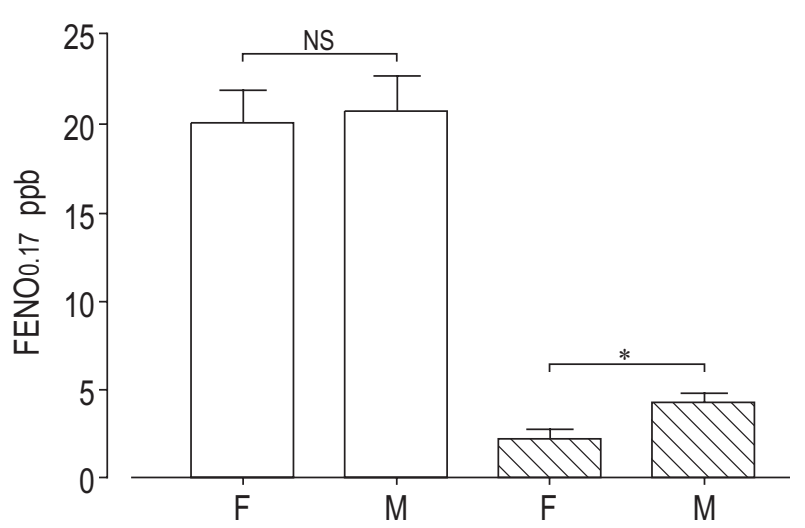

Fig. 4. - NO in nasally $(\square)$ and orally $(\mathbb{\mathbb { N }})$ exhaled air of eight healthy males and seven healthy females. Values are presented as the mean of measurements at three time-points on one single day. NS: nonsignificant; *: $\mathrm{p}=0.01$, Mann Whitney U test; F: female; M: male; FENO0.17: exhale concentration of $\mathrm{NO}$ at a flow rate of $0.17 \mathrm{~L} \cdot \mathrm{s}^{-1}$; ppb: parts per billion.

3a). Notably, if the mean NO output values $\left(\mathrm{nL} \cdot \mathrm{min}^{-1}\right)$ in air exhaled through the right and left nostril were added the levels would be more than double, compared to exhalation through both nostrils at the same time, with a percentage increase of $115 \%$. There was a strong correlation between levels of NO in air exhaled through the right or left nostril (fig. 3b). There was a difference between males and females in levels of NO in orally exhaled air but no difference in nasally exhaled air (fig. 4). There was no correlation between body surface area and NO in nasally or orally exhaled air $(r=-0.33, p=0.22$ and $\mathrm{r}=0.33, \mathrm{p}=0.22$ respectively; Spearman rank correlation).

\section{Effects of a mouthwash}

The levels of NO in nasally exhaled air were unaffected by the mouthwash, whereas there was a $19 \%$ reduction of NO in orally exhaled air after the mouthwash procedure (fig. 5). Furthermore, there was a $22 \%$ reduction of the methodological variability as described by the withinsubject CV of NO in orally exhaled air before and after mouthwash $(12 \pm 1.1$ versus $10 \pm 0.9$; $\mathrm{p}<0.0001$; Wilcoxon

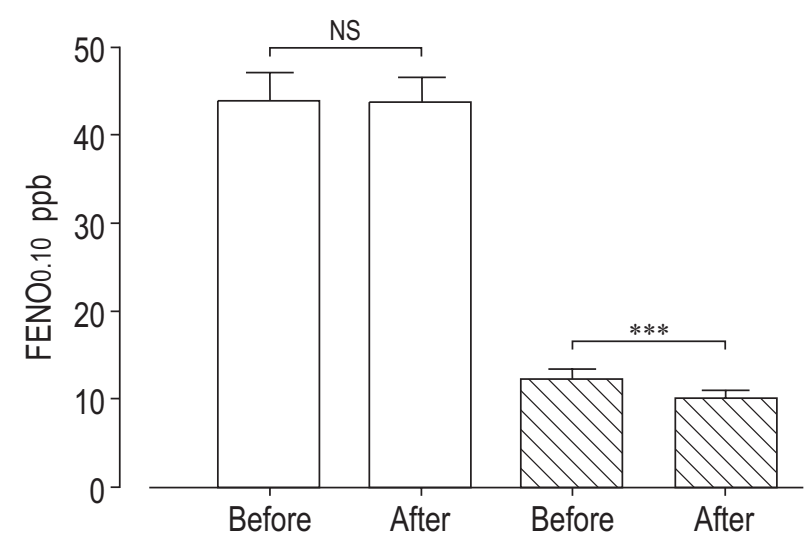

Fig. 5. - a) Consistent levels of NO before and after mouthwash in nasally ( $\square$ ) exhaled air and a $19 \%$ reduction in levels of NO in orally $(\mathbb{\otimes})$ exhaled air of 25 healthy subjects after mouthwash. Ns: nonsignificant; * $\mathrm{p}<0.0001$, Wilcoxon signed rank sum test; FENO0.10: exhaled concentration of $\mathrm{NO}$ at a flow rate of $0.10 \mathrm{~L} \cdot \mathrm{s}^{-1}$; ppb: parts per billion. signed rank sum test). Thus, the mouthwash procedure reduces both oral contribution to and methodological variation in the measurements of NO in orally exhaled air.

\section{Discussion}

This study aimed to characterize diurnal and day-to-day biological variability in exhaled NO levels and to assess the feasibility of improving the accuracy of the measurement technique itself by using a mouthwash procedure and introducing an alternative method for the measurement of nasal NO.

Nasal (supravelum) measurement techniques have been extensively discussed and consensus has been reached on what methods should be used $[14,16]$. However, no clearcut explanations of what is being measured and why different measurements yield different NO outputs at different flow rates have been put forward $[15,18,19]$. In the present study healthy young subjects performing exhalations in a highly reproducible way were examined. When applying this single-breath method to patients with disease, greater variations in the exhalations will probably be accepted, and must therefore expect a larger variability in measurements. The proposed subtraction method might offer a step in the right direction towards reproducibility, but requires participation of the studied subject, elimination of oral NO and at least two measurements. If nasal NO measurements find their way into daily clinical practice, perhaps different methods will be preferable in various situations.

Anatomical variations such as supravelum space volume and sinus ostiae diameter, as well as metabolic or dietary factors may influence NO output in the airways. There may also be a variation in inducible NO synthase (iNOS) expression in the airway epithelium between subjects, independent of inflammatory processes $[20,21]$. The individual NO values were consistent over one week for both orally and nasally exhaled air. This may indicate that it would be preferable for subjects to be their own controls in studies on exhaled and nasal NO in small numbers of patients.

Diurnal variation, with a rise in the NO levels in nasally and orally exhaled air over the day might be explained by dietary [17] as well as metabolic factors. A reduced level in the morning might be attributed to exercise (walking) [22], but the resting time allowed in this study should have ruled this out.

The high day-to-day repeatability indicates that the methods used in this study for measurements of exhaled and nasal NO were robust. Interestingly, a reduction in the average orally exhaled NO level was noted on the morning of day 7, which was a Monday. This may indicate a relationship between NO and stress or exposure to environmental factors like allergen or pollution [23, 24]. The authors conclude that this reduction was not due to drift in the setup, since some subjects showed a decrease while others showed an increase between the days 3 and 7 .

A sex difference in orally exhaled air, with lower levels of NO in females, supports the findings in at least two previous studies $[25,26]$ and may be due to dietary or metabolic factors. That the difference between males and females is related to sex, and not to height and weight, is supported by the finding that there was no correlation between body surface area and oral or nasally exhaled 
NO, suggesting a nonlinear relationship between body surface area and exhaled NO levels. This may indicate that subjects and controls will have to be matched with regard to sex but not to height or weight in future studies on exhaled NO and when establishing normal values.

The levels of NO in nasally exhaled air were higher when the subject exhaled with the same volume flow rate through the right or the left nostril separately than when he or she exhaled through both nostrils at the same time. This result was unexpected. Spillover from the occluded side behind the nasal septum cannot explain this, because the levels should still be reduced compared to exhaling through both nostrils. Even though a higher air speed will generally lead to a greater probability for turbulence near the nasal mucosa, and thus possibly an increased gas exchange, it is hypothesized that the increased air speed when the subject exhaled through only one nostril, leads to larger contribution from the paranasal sinuses, where large NO reserves are present. A larger contribution from the sinuses could be explained by a more turbulent flow generated around the nasal conchae leading to increased negative pressure outside paranasal sinus ostiae. This may indicate that air speed will have to be taken into consideration in future nasal NO measurements and that different methods at different volume flow rates measure different aspects of nasal NO release. Interestingly, two studies on allergic rhinitis show an increase in nasal NO $[6$, 27], while two show no difference in nasal NO [7, 12].

The rationale for the proposed definition of nasal $\mathrm{NO}$ in this study as the mean level of NO in orally exhaled air after mouthwash subtracted from the mean level of NO in orally exhaled air after mouthwash subtracted from the mean level of NO in nasally exhaled air could briefly be described as follows: NO in nasally exhaled air may originate from three constantly connected and presumably NO producing airway compartments: 1) the nasal cavity, paranasal sinuses and nasopharynx (supravelum space); 2) the passage through the oropharynx, including the posterior side of the lowered soft palate; and 3) the lower airways from hypopharynx and below. NO in orally exhaled air may also originate from three compartments: 1) the oral cavity; 2) the oropharynx, including the anterior side of an elevated soft palate; and 3) the lower airways from hypopharynx and below. If we assume the contribution to levels of NO in nasally exhaled air from the fairly small region of the oropharynx with the posterior side of a lowered soft palate to be equal to the contribution to levels of NO in orally exhaled air from the oropharynx with the anterior side of an elevated soft palate. And, if it is assumed that the contribution from the lower airways from the hypopharynx and further down, to be equal when in nasally and orally exhaled air, and if, finally, it is assumed that the contribution from the oral cavity to be reduced to $\sim 0$ after mouthwash [17], the contribution from the nasal cavity, paranasal sinuses and nasopharynx (supravelum space) equals NO in nasally exhaled air minus the levels of NO in orally exhaled air after mouthwash. Furthermore, it may be that nasal NO output is more dependent on airflow dynamics than the concentration gradient between luminal air and airway mucosa. Assuming this is the case it would be acceptable to subtract as suggested. However, in clinical practice an optimal mouthwash solution will be needed, reducing oral contribution to exhaled NO to zero.
An advantage of the suggested nose-mask method for the recording of nasal NO compared to the method using direct nasal aspiration as recommended by the ATS [14] is the better possibility of inhalation of NO-free air in times of and places with high ambient NO levels [28, 29]. High ambient levels of NO could also be a reason to add a second nasal olive for the introduction of NO-free air to the ATS recommendations. Furthermore, when the alternative recommended method of insufflating air into one nostril [14] was used, some of the healthy controls in study 1 could not tolerate the flow rate of $3 \mathrm{~L} \cdot \mathrm{min}^{-1}$ due to discomfort and failed to keep the soft palate closed (unpublished data). The authors also detected a significant difference in nasal NO levels when using two nasal olives of different inner diameter, possibly due to changes in the turbulence of the transnasal airflow (unpublished data). Thus, it could be argued that a nasal exhalation better reflects normal physiological conditions for transnasal airflow than the aspiration/insufflation methods. The single-breath method is widely accepted for oral exhalations and the nose-mask was well tolerated [19] and easily adapted to the setup for oral measurements.

The finding that a mouthwash procedure reduces oral contribution to the measurements of NO in orally exhaled air was expected and confirms the findings of ZETTERQUIST et al. [17]. This, together with the reduction in methodological variation, indicates that elimination of oral NO would be preferable in future studies on orally exhaled NO. The reason the mean methodological variability of orally exhaled NO was lower without mouthwash in study 1 than in study 2, both before and after mouthwash, might be the use of a higher flow rate and the subjects acquiring skills due to the large amount of repeated measurements undertaken.

In conclusion, this study shows that the NO levels in nasally and orally exhaled air of healthy human adults are clearly individual, with almost a 3-fold inter-individual difference in levels of NO in nasally exhaled air and a 10fold inter-individual difference in levels of $\mathrm{NO}$ in orally exhaled air. This study also shows a rise in the NO levels in nasally and orally exhaled air over the course of the day. A relative consistency between the levels measured on three separate mornings but with a significant decrease after the weekend in orally exhaled air was also observed. Also shown in this study is a sex difference in orally exhaled air, with lower levels of NO in females, which was not related to body surface area. The levels of NO in nasally exhaled air were higher when subjects were exhaling through either the right or the left nostril separately than when they exhaled through both nostrils at the same time, despite similar volume air flow. The mouthwash procedure did not influence levels of nasally exhaled $\mathrm{NO}$, whereas it reduced both oral contribution to and methodological variation in the measurements of NO in orally exhaled air. The authors conclude that the suggested subtraction method is a valid and highly reproducible method for the measurement of nasal NO.

\footnotetext{
Acknowledgements. The authors would like to thank the participants in this study, including all personnel at research department M61 at Huddinge University Hospital.
} 


\section{References}

1. Gustafsson LE, Leone AM, Persson MG, Wiklund NP, Moncada S. Endogenous nitric oxide is present in the exhaled air of rabbits, guinea pigs and humans. Biochem Biophys Res Commun 1991; 181: 852-857.

2. Alving K, Weitzberg E, Lundberg JM. Increased amount of nitric oxide in exhaled air of asthmatics. Eur Respir $J$ 1993; 6: 1368-1370.

3. Lundberg JO, Farkas-Szallasi T, Weitzberg E, et al. High nitric oxide production in human paranasal sinuses. Nat Med 1995; 1: 370-373.

4. Chatkin JM, Qian W, McClean PA, Zamel N, Haight J, Silkoff P. Nitric oxide accumulation in the nonventilated nasal cavity. Arch Otolaryngol Head Neck Surg 1999; 125: 682-685.

5. Lewandowski $\mathrm{K}$, Busch $\mathrm{T}$, Lohbrunner $\mathrm{H}$, et al. Low nitric oxide concentrations in exhaled gas and nasal airways of mammals without paranasal sinuses. $J \mathrm{Appl}$ Physiol 1998; 85: 405-410.

6. Arnal JF, Didier A, Rami J, et al. Nasal nitric oxide is increased in allergic rhinitis. Clin Exp Allergy 1997; 27: 358-362.

7. Henriksen AH, Sue-Chu M, Lingaas Holmen T, Langhammer A, Bjermer L. Exhaled and nasal NO levels in allergic rhinitis: relation to sensitization, pollen season and bronchial hyperresponsiveness. Eur Respir J 1999; 13: 301-306.

8. Imada M, Iwamoto J, Nonaka S, Kobayashi Y, Unno T. Measurement of nitric oxide in human nasal airway. Eur Respir J 1996; 9: 556-559.

9. Ferguson EA, Eccles R. Changes in nasal nitric oxide concentration associated with symptoms of common cold and treatment with a topical nasal decongestant. Acta Otolaryngol 1997; 117: 614-617.

10. Rinder J. Sensory neuropeptides and nitric oxide in nasal vascular regulation. Acta Physiol Scand Suppl 1996; 632: $1-45$.

11. Lundberg JO, Weitzberg E, Nordvall SL, Kuylenstierna $\mathrm{R}$, Lundberg JM, Alving K. Primarily nasal origin of exhaled nitric oxide and absence in Kartagener's syndrome. Eur Respir J 1994; 7: 1501-1504.

12. Lundberg JO, Nordvall SL, Weitzberg E, Kollberg H, Alving K. Exhaled nitric oxide in paediatric asthma and cystic fibrosis. Arch Dis Child 1996; 75: 323-326.

13. Palm JP, Lidman C, Graf P, Lundberg JO, Alving K. Nasal nitric oxide is reduced in patients with HIV. Acta Otolaryngol (In press).

14. Slutzky AS, Drazen JM, Silkoff PE, et al. Recommendations for standardized procedures for the online and offline measurement of exhaled lower respiratory nitric oxide and nasal nitric bride in adults and children - 1999. Am J Respir Crit Care Med 1999; 160: 2104-2117.

15. Bartley J, Fergusson W, Moody A, Wells AU, Kolbe J.
Normal adult values, diurnal variation, and repeatability of nasal nitric oxide measurement. Am J Rhinol 1999; 13: 401-405.

16. Kharitonov S, Alving K, Barnes PJ. Exhaled and nasal nitric oxide measurements: recommendations. The European Respiratory Society Task Force. Eur Respir J 1997; 10: 1683-1693.

17. Zetterquist W, Pedroletti C, Lundberg JO, Alving K. Salivary contribution to exhaled nitric oxide. Eur Respir J 1999; 13: 327-333.

18. Djupesland PG, Chatkin JM, Qian W, et al. Aerodynamic influences on nasal nitric oxide output measurements. Acta Otolaryngol 1999; 119: 479-485.

19. Silkoff PE, Chatkin J, Qian W, et al. Nasal nitric oxide: a comparison of measurement techniques. Am J Rhinol 1999; 13: 169-178.

20. Furukawa K, Harrison DG, Saleh D, Shennib H, Chagnon FP, Giaid A. Expression of nitric oxide synthase in the human nasal mucosa. Am J Respir Crit Care Med 1996; 153: 847-850.

21. Tasman AJ, Bogatzki B, Heppt W, Hauser-Kronberger C, Fischer A. Nitric oxide synthase in the innervation of the human nasal mucosa: correlation with neuropeptides and tyrosine hydroxylase. Laryngoscope 1998; 108: 128-133.

22. Lundberg JO, Rinder J, Weitzberg F, Alving K, Lundberg JM. Heavy physical exercise decreases nitric oxide levels in the nasal airways in humans. Acta Physiol Scand 1997; 159: 51-57.

23. Steerenberg PA, Snelder JB, Fischer PH, Vos JG, van Loveren H, van Amsterdam JG. Increased exhaled nitric oxide on days with high outdoor air pollution is of endogenous origin. Eur Respir J 1999; 13: 334-337.

24. Baraldi E, Carra S, Dario C, et al. Effect of natural grass pollen exposure on exhaled nitric oxide in asthmatic children. Am J Respir Crit Care Med 1999; 159: 262-266.

25. Jilma B, Kastner J, Mensik C, et al. Sex differences in concentrations of exhaled nitric oxide and plasma nitrate. Life Sci 1996; 58: 469-476.

26. Morris NH, Sooranna SR, Steer PJ, Warren JB. The effect of the menstrual cycle on exhaled nitric oxide and urinary nitrate concentration. Eur J Clin Invest 1996; 26: 481484.

27. Kharitonov SA, Rajakulasingam K, O'Connor B, Durham SR, Barnes PJ. Nasal nitric oxide is increased in patients with asthma and allergic rhinitis and may be modulated by nasal glucocorticoids. J Allergy Clin Immunol 1997; 99: 58-64.

28. Dubois AB, Douglas JS, Stitt JT, Mohsenin V. Production and absorption of nitric oxide gas in the nose. J Appl Physiol 1998; 84: 1217-1224.

29. Kelley PM, DuBois AB. Comparison between the uptake of nitrous oxide and nitric oxide in the human nose. $J$ Appl Physiol 1998; 85: 1203-1209. 